\title{
The Dilemma of Intellectual Property Agreements and R\&D in Developing Economies: A Game Theory Approach
}

\author{
Mhamed-Ali El-Aroui $^{1}$ (D) Selma Dellagi ${ }^{2} \cdot$ Fouad Ben Abdelaziz $^{3}$
}

Accepted: 29 June 2021 / Published online: 7 July 2021

(c) The Indian Econometric Society 2021

\begin{abstract}
This paper models and predicts how the strengthening of intellectual property (IP) protection will impact $R \& D$ in developing economies. International agreements such as TRIPs and free trade agreements are enhancing the level of international control on IP. This is changing deeply the R\&D environment in developing economies by restraining illegal channels of knowledge accumulation such as imitation, reverse engineering and piracy. An asymmetric and non-cooperative two-stage (R\&D-Production) game is proposed to model a developing market where two local firms compete with a more innovative foreign firm. Equilibrium R\&D expenditures and profits of the competing firms are compared for different levels of: market technology, technological gaps and IP protection. The proposed model shows clearly that a stringent enforcement of IP agreements will dramatically decrease the innovative abilities of developing economies especially in high technological sectors. The maintain and increase of their R\&D skills will not be possible without a reduction of their technological gap and strong incentives to initiate regulatory (or permit tacit) $\mathrm{R} \& \mathrm{D}$ cooperation between local firms.
\end{abstract}

Keywords Innovation - Imitation · Development $\cdot$ TRIPs $\cdot$ R\&D $\cdot$ Intellectual Property

JEL Classifications $\mathrm{O} 32 \cdot \mathrm{O} 34 \cdot \mathrm{C} 72 \cdot \mathrm{O} 12$

Mhamed-Ali El-Aroui

mhamed-ali.elaroui@uir.ac.ma; mhamed.elaroui@planet.tn

1 Rabat Business School, International University of Rabat, Technopolis, Sala-Jadida 11100, Morocco

2 ISG de Tunis, University of Tunis, Av. de la Liberté, Le Bardo 2000, Tunisia

3 Neoma Business School, 1 Rue Marechal Juin, Mont-Saint-Aignan 76825, France 


\section{Introduction}

Research and Development (R\&D) is the basis of growth and competitiveness in high technological sectors. R\&D can be undertaken either in or outside the firm by means of transfer, licensing, spillovers (unintended technology transfer) or by the formation of R\&D strategic alliances (cooperation). The main goal of the present work is to develop a game theory model to analyse the effects of stronger intellectual property (IP) rights on domestic $\mathrm{R} \& \mathrm{D}$ and innovation in developing and less developed economies.

Recent international agreements such as TRIPs (Trade Related aspects of Intellectual Property rights protection) and the several multilateral free trade agreements (FTAs) are enhancing the level of international control on IP.

With this increasing IP protection, developed countries (denoted hereafter DCs) will have more incentives to undertake R\&D activities since their innovations are better protected all over the world. But this is (at least in the short term) penalizing less developed countries (denoted in the following LDCs) which used to have an affordable access to recent innovations and technologies by means of illegal or indirect transfer (or R\&D spillovers). The present and future impacts of international IP agreements on the welfare and economic development of LDCs are not clear and are currently debated by innovation economists and intellectual property experts.

Few game-theory models were used to contribute theoretically to the previous debates. Yang and Maskus (2009) for example developed a Cournot competition model to analyse how stronger intellectual property rights protection could improve the ability of firms in developing countries to break into export markets. They conclude that stronger intellectual property rights would be beneficial only to developing countries with high absorptive capacity.

Several theoretical works modelled the impact of spillovers on R\&D strategies, see for example Amir (2000), Cincera and Van Pottelsberghe de la Potterie (2001), Miyagiwa and Ohno (2002), Tang and Koveos (2008) and Aldieri et al. (2018).

In their seminal work, d'Aspremont and Jacquemin (1988) and Kamien et al. (1992) presented different forms of R\&D strategic alliances defined on the basis of cooperation or competition in a two-stage game (production stage and R\&D stage). Both papers modelled R\&D strategies by considering different rates of spillover between the different firms.

The present model extends the framework of d'Aspremont and Jacquemin (1988) to analyse the impact of higher IP protection on R\&D strategies of LDCs and DCs firms competing in a local LDCs market where a high level IP product has to be designed for specific LDCs needs: medicines for regional diseases, local agricultural plant varieties or pest treatments, technological answers to specific climatic threats such as drought and desertification, etc. R\&D expenditures and profits of DCs and LDCs firms are compared in different scenarios where several key innovation factors are considered: the technological level of the modelled market, the importance of the technological gap between DCs and LDCs firms and the strength of IP protections internationally (inter) and locally (intra). 
The following section presents a short survey of the literature connecting innovation, development and IP rights. The suggested model, described in "Modelling competition in LDC technological markets", is asymmetric since LDCs firms are supposed to have less innovative skills than their foreign rivals. In "Modelling TRIPs' effects on profits and R\&D”, our game-theoretic model is used to compare equilibrium profits and R\&D expenditures of both LDCs and DCs firms. It is shown that the competitiveness of LDCs firms in local high-tech markets will strongly depend on their technological backwardness and on how IP will be enforced for local and international irregular knowledge exchanges. Finally, "Discussion and conclusion" discusses strategies LDCs should adopt in this new context of stronger IP rights. Conclusions and further research tracks are also presented.

\section{IP Rights, Innovation and Development}

One of the most important problems discouraging innovative foreign firms from undertaking R\&D dedicated to specific local needs of less developed markets is the difficulty to protect intellectual property. Cooperation can internalise the effects of spillovers only when the technological gap between foreign and LDCs firms is not important and when IP protection is stringent.

During the 1990's many developed countries asked, during WTO negotiations, for more international IP protection. This problem was discussed during the GATT (General Agreement on trade and tariffs) meetings (especially the Uruguay Round in 1994 and the Doha Ministerial Conference in 2001). As a result, WTO members established TRIPs agreement that, at least theoretically, should control, protect and stimulate international innovations. TRIPs was signed in 1994 by more than one hundred WTO members and came into force in 1995 for developed economies and in 2006 (2016 for pharmaceuticals) for developing countries.

More than two decades later, and despite the continuous strengthening of IP norms through the numerous north-south FTAs (like the TRIPS-plus provisions), several less developed states still offer IP systems with high quality law on the books but low quality law in practice [(see Papageorgiadis and McDonald (2019)]. TRIPs and FTAs will nevertheless soon or late constrain developing states to provide effective enforcement provisions against serious IP infringements. This is starting for example with China and its recent frictions with other WTO members and particularly USA.

TRIPs was initially designed to protect intellectual property and 'consequently' promote innovation and R\&D activities in both developed and developing countries but its real consequences on the innovative ecosystem in LDCs are currently strongly questioned. These consequences have generated heated debates, see for example Drahos and Braithwaite (2002), Chen and Puttitanum (2005), Forero-Pineda (2006), Murray and Stern (2007), Kim et al. (2012), Hudson and Minea (2013), Morin and Gold (2014), Sweet and Eterovic-Maggio (2015), Campi and Dueñas (2019), Sweet and Eterovic (2019) and Correa and Seuba (2019) among a flourishing literature on development, innovation and IP. 
Some authors see that these agreements will undoubtedly increase the technological gap of LDCs with dramatic consequences on health, nutrition, education and technology. Maskus and Konan (1994) for example predicted that protection of IP rights could imply an increase in the prices of medicines by $25-67 \%$ which would decrease affordable access to health in developing countries. This was confirmed recently by the difficulties of LDCs to get COVID-19 vaccines and the debate between international political leaders about possible waiving of COVID-19 vaccine patents.

Others on the contrary see that such agreements will encourage local R\&D and initiate new local and legal innovative dynamics in LDCs. As it was mentioned by Bouet (2015), several works argue that stronger IP protection will enhance ' accumulation and diffusion of corporate business practices including the productivity of research and interactions between universities and the business community'. The latter point of view is sustained by the fact that TRIPs includes many provisions giving LDCs special rights for a transition period and requiring DCs governments to incite their firms to transfer technology to LDCs.

As it was suggested by Cho et al. (2015), this lack of consensus concerning the impact of international IP agreements in LDCs is due to two opposing effects of stronger IP rights on innovation. An incentive effect since innovators will get more profits and could innovate more; foreign firms will have more incentives to work on high technological needs of LDCs. But stronger IP protection will also have an inhibitory effect with less diffusion and combination of new ideas and inventions. Thus, to rise innovation, governments should maximize the former effect while minimizing the latter. Considering this duality, several studies [cited by Cho et al. (2015)] have investigated key innovation factors including IP rights, and have suggested that the effects of IP on innovation vary by country, industry, stage of economic development and type of IP rights, among other factors.

Many international experts criticized the emerging globaly harmonized IP system which does not take into account the asymmetric positions of DCs and LDCs. Drahos and Braithwaite (2002) and Drahos (2005) stressed the negative effects of TRIPs on LDCs. They concluded that 'globalization of intellectual property really only benefited the US and to a lesser extent the European Community' and that the reason 'developing countries signed TRIPs has much to do with the failure of democracy both nationally and internationally'. They elaborated a proposal for a new framework of intellectual property right protection where cooperative solutions and democratic bargaining among states will give LDCs a fairer access to knowledge.

According to Morin and Gold (2014), developed and developing countries have very different IP optima. Knowledge economies seek to maintain their economic advantage by providing and promoting strong IP standards. While LDCs have an interest in providing lower levels of IP protection so that local firms could acquire foreign technologies and ensure low retail prices. Morin and Gold (2014) conclude clearly that 'When judged solely on the basis of economic interests, IP rules should differ significantly between developed and developing countries but despite these asymmetries of interest, IP has become increasingly harmonized globally'. Sampath (2019) ascertained a 'persistent (and worsening) lack of balance in the global intellectual property system'. 
In the following section, a game theoretical model is developed to bring some theoretical elements to the previous debate. The suggested model will predict how IP agreements will probably affect R\&D in LDCs. The obtained results could be used to suggest new policies decision makers in LDCs should initiate so that local firms could meet the challenges of stronger IP rights.

\section{Modelling Competition in LDC Technological Markets}

The game described hereafter models an R\&D competition between three firms concerning a single good or service with a high IP component. The product is mainly requested in a less developed country (LDC) where two local firms (denoted firm 1 and firm 2) are in competition with a foreign firm (either multinational or from a DC) (denoted firm 3) closer to the innovative frontier. This game with three players is used to model the spillovers' effects (inter: from DC to LDC and intra: within LDC) on firms' profits and R\&D spending.

\section{Modelling Context and Assumptions}

It will be assumed in the following that the three firms produce a single high IP product distributed mainly in the LDC market with a single price. In order to focus on $R \& D$ impact on firms profits it will be assumed that, before this R\&D stage, the three firms have a common unit cost of production denoted $c$.

Following d'Aspremont and Jacquemin (1988) and Kamien et al. (1992), a twostage game (R\&D and production) is used. At the first (R\&D) stage the three firms conduct R\&D to reduce their production costs. They choose competitively their $\mathrm{R} \& \mathrm{D}$ expenditures or equivalently their $\mathrm{R} \& \mathrm{D}$ levels $x_{1}, x_{2}$ and $y \in[0, c]$ representing respectively the reduction of the unit production cost of firms 1,2 and 3 due only to their own R\&D effort. At the second (production) stage firms are assumed to be Cournot-competitors. The proposed game is a one shot game, players take their decision considering the fact that this is not a repeated game.

The R\&D game is competitive since it is assumed that LDCs have not yet the legal and institutional framework encouraging firms to undertake cooperative R\&D.

Two types of spillovers are considered: intra and inter spillovers. The DC firm is assumed to be at the innovative frontier and receives no spillover from LDC firms. The two LDC firms are assumed to have the same absorptive and innovative abilities and the same strategy toward illegal knowledge transfer. This strategy is strongly determined by the local cultural and legal environment. It will be assumed therefore that both LDC firms receive the same inter spillover from the DC firm. It will be assumed also that the intra spillovers exchanged between firms 1 and 2 are symmetric.

As in d'Aspremont and Jacquemin (1988), R\&D effort is modelled by cost reduction. The effective marginal cost reduction of $\operatorname{LDC}$ firm $i(i \in\{1,2\})$ is modelled here by : 


$$
X_{i}=x_{i}+\beta x_{j}+\delta y \text { for } j \in\{1,2\} \text { with } j \neq i \text {, }
$$

while the effective marginal cost reduction of the DC firm is : $Y=y$.

Notations: the notations below will be used in what follows

- For $i \in\{1,2\}, x_{i}$ denotes the cost reduction of LDC firm $i$ due to its own R\&D effort.

- $y$ denotes the cost reduction of the DC firm due to its own R\&D effort.

- $\beta$ denotes the intra spillover between the two LDC firms; $\beta \in[0,1]$.

- $\delta$ denotes the inter spillover from the DC firm to the LDC firms; $\delta \in[0,1]$.

It is assumed that the three firms face the same linear inverse demand function:

$$
P\left(q_{1}, q_{2}, q_{3}\right)=a-q_{1}-q_{2}-q_{3} \equiv a-Q
$$

where $q_{i}$ is the quantity produced by firm $i ; i \in\{1,2,3\}$ and $a$ is a non-negative constant such that $a>c$.

Each firm $i \in\{1,2\}$ has a total production cost depending on its own production $q_{i}$, on the amount of its research $x_{i}$, and the research efforts $x_{j}$ and $y$ of its rivals:

$$
C_{i}\left(q_{i}, x_{i}, x_{j}, y\right)=\left[c-x_{i}-\beta x_{j}-\delta y\right] q_{i} .
$$

DC firm has a cost of production:

$$
C_{3}\left(q_{i}, x_{i}, x_{j}, y\right)=[c-y] q_{3} .
$$

Consequently, each LDC firm $i \in\{1,2\}$ has a profit modelled by:

$$
\pi_{i}=\left(a-Q-c+X_{i}\right) q_{i}-\frac{1}{2} \gamma_{L D C} x_{i}^{2} .
$$

DC firm has the following profit :

$$
\pi_{3}=(a-Q-c+Y) q_{3}-\frac{1}{2} \gamma_{D C} y^{2} .
$$

with the following notations:

Notations:

- $Q=q_{1}+q_{2}+q_{3}$ is the total quantity produced by the three firms.

- $c-X_{i}$ is firm $i$ 's $(i \in\{1,2\})$ marginal cost of production after R\&D activities and imitation.

- $\gamma_{L D C}$ is the marginal cost of R\&D activities in LDC firm: R\&D cost function in LDC firm is modelled by $\frac{1}{2} \gamma_{L D C} x_{i}^{2}$. This yields diminishing marginal returns of R\&D. More precisely an investment of $\frac{1}{2} \gamma_{L D C} x_{i}^{2}$ is needed to reduce the cost of production by $x_{i}$. It is assumed here that the two LDC firms have the same technological and absorptive abilities.

- $c-Y$ : firm 3 marginal cost of production after R\&D activities. 
- $\gamma_{D C}$ is the marginal cost of $\mathrm{R} \& \mathrm{D}$ activities in DC. The R\&D cost function of the DC firm is here modelled by $\frac{1}{2} \gamma_{D C} y^{2}$.

An asymmetric non-cooperative game is developed where $\left(x_{1}, x_{2}, y\right)$ and $\left(q_{1}, q_{2}, q_{3}\right)$ are set simultaneously and are chosen non-cooperatively. This game is solved considering the Cournot-Nash equilibrium in the production stage and the Nash equilibrium in the R\&D stage. The assumptions below are used in all the following.

\section{Assumptions}

1. It is assumed that the DC firm has a significant technological advance and consequently R\&D marginal cost is higher for LDC firms. So only cases where $\gamma_{L D C}>\gamma_{D C}$ will be considered.

2. The value of R\&D marginal cost in DC $\left(\gamma_{D C}\right)$ is used in Sect. 4 to comment our results. As firm 3 is assumed to be very close to the innovative frontier, its R\&D marginal cost $\gamma_{D C}$ will be used as an indicator of the technological value of the studied sector. Low values of $\gamma_{D C}$ model low technological markets, when high values of $\gamma_{D C}$ are related generally to sectors with high technological value.

\section{Production Stage Equilibrium}

In the market stage (second stage of the game) it is assumed that firms play simultaneously. Considering, backward induction, the market stage is solved for given values of $\mathrm{R} \& \mathrm{D}$ expenditures $x_{1}, x_{2}$ and $y$.

To find the Cournot-Nash equilibrium, the following equations, representing the first order conditions (FOC) are solved simultaneously

$$
\left\{\begin{array}{l}
\frac{\partial \pi_{1}}{\partial q_{1}}=a-2 q_{1}-q_{2}-q_{3}-c+X_{1}=0 \\
\frac{\partial \pi_{2}}{\partial q_{2}}=a-2 q_{2}-q_{1}-q_{3}-c+X_{2}=0 \\
\frac{\partial \pi_{3}}{\partial q_{3}}=a-2 q_{3}-q_{1}-q_{2}-c+Y=0
\end{array}\right.
$$

this yields the following Cournot-Nash equilibrium quantities:

$$
\left\{\begin{array}{l}
q_{1}=\frac{a-c+x_{1}(3-\beta)+x_{2}(3 \beta-1)+y(2 \delta-1)}{4} \\
q_{2}=\frac{a-c+x_{2}(3-\beta)+x_{1}(3 \beta-1)+y(2 \delta-1)}{4} \\
q_{3}=\frac{a-c+y(3-2 \delta)-x_{1}(1+\beta)-x_{2}(1+\beta)}{4}
\end{array}\right.
$$

By replacing in Eqs. (5) and (6) $q_{i}$ 's by their equilibrium values given by Eq. (8), the profit functions write: 


$$
\left\{\begin{array}{l}
\pi_{1}=\frac{1}{16}\left[a-c+(3-\beta) x_{1}+(3 \beta-1) x_{2}+(2 \delta-1) y\right]^{2}-\frac{1}{2} \gamma_{L D C} x_{1}{ }^{2} \\
\pi_{2}=\frac{1}{16}\left[a-c+(3-\beta) x_{2}+(3 \beta-1) x_{1}+(2 \delta-1) y\right]^{2}-\frac{1}{2} \gamma_{L D C} x_{2}{ }^{2} \\
\pi_{3}=\frac{1}{16}\left[a-c-(1+\beta) x_{1}-(1+\beta) x_{2}+(3-2 \delta) y\right]^{2}-\frac{1}{2} \gamma_{D C} y^{2}
\end{array}\right.
$$

Equations (9) will be used hereafter to find the equilibrium R\&D levels at the R\&D stage.

\section{R\&D Stage Equilibrium}

In the R\&D stage (first stage of the game) firms decide non-cooperatively on their R\&D levels. The FOC's are:

$$
\left\{\begin{array}{l}
\frac{\partial \pi_{1}}{\partial x_{1}}=\frac{1}{8}\left(a-c+(3-\beta) x_{1}+(3 \beta-1) x_{2}+(2 \delta-1) y\right)(3-\beta)-\gamma_{L D C} x_{1}=0 \\
\frac{\partial \pi_{2}}{\partial x_{2}}=\frac{1}{8}\left(a-c+(3-\beta) x_{2}+(3 \beta-1) x_{1}+(2 \delta-1) y\right)(3-\beta)-\gamma_{L D C} x_{2}=0 \\
\frac{\partial \pi_{3}}{\partial y}=\frac{1}{8}\left(a-c-(1+\beta) x_{1}-(1+\beta) x_{2}+(3-2 \delta) y\right)(3-2 \delta)-\gamma_{D C} y=0
\end{array}\right.
$$

The previous equations yield the best-response functions ( $R \& D$ results) of firms 1,2 and 3 denoted respectively: $x_{1}=b_{1}\left(x_{2}, y\right), x_{2}=b_{2}\left(x_{1}, y\right)$ and $y=b_{3}\left(x_{1}, x_{2}\right)$.

Remark As the two LDC firms are assumed to have the same technological ability, it will be assumed also that they will adopt the same R\&D strategy $\left(x_{1}=x_{2}\right)$. This common strategy will be mainly determined by the technological, political, economical and legal environments prevailing in the LDC.

Computing the intersection of the three best-response functions, and considering symmetric solutions for the LDC firm $\left(x_{1}=x_{2}\right)$, yield the following Nash equilibrium R\&D levels :

$$
\begin{aligned}
& \hat{x}_{1}=\hat{x}_{2}=-(-3+\beta)\left(5 \delta-2 \delta^{2}+2 \gamma_{D C}-3\right)(a-c) /\left(4 \gamma_{D C} \beta^{2}-3 \beta^{2}\right. \\
&+2 \delta \beta^{2}-4 \beta \delta+6 \beta-8 \gamma_{D C} \beta+9+16 \gamma_{D C} \gamma_{L D C}-12 \gamma_{D C} \\
&\left.-6 \delta+24 \gamma_{L D C} \delta-18 \gamma_{L D C}-8 \delta^{2} \gamma_{L D C}\right) \\
& \hat{y}=-\left(\beta^{2}-2 \beta-3+2 \gamma_{L D C}\right)(-3+2 \delta)(a-c) /\left(4 \gamma_{D C} \beta^{2}-3 \beta^{2}+2 \delta \beta^{2}\right. \\
&-4 \beta \delta+6 \beta-8 \gamma_{D C} \beta+9+16 \gamma_{D C} \gamma_{L D C}-12 \gamma_{D C} \\
&\left.-6 \delta+24 \gamma_{L D C} \delta-18 \gamma_{L D C}-8 \delta^{2} \gamma_{L D C}\right)
\end{aligned}
$$

The second-order condition requires that: 


$$
\frac{\partial^{2} \pi_{i}}{\partial x_{i}^{2}}<0, \text { for } i \in\{1,2\} \quad \text { and } \quad \frac{\partial^{2} \pi_{3}}{\partial y^{2}}<0
$$

and consequently:

$$
\left\{\begin{array}{l}
(3-\beta)^{2}-8 \gamma_{L D C}<0 \\
(3-2 \delta)^{2}-8 \gamma_{D C}<0
\end{array}\right.
$$

\section{Modelling TRIPs' Effects on Profits and R\&D}

The previous model, with its equilibrium $R \& D$ levels and production quantities, is used to analyse the effects of different levels of IP protection on R\&D expenditures and profits in LDC markets. Several levels of inter and intra spillovers will be considered and related to different ways IP international agreements will be enforced. The technological gap separating DC and LDC firms and the technological complexity of the modelled sector will be important factors in the following analysis. Cho et al. (2015) for example found that industry differences are very important when studying the effects of stronger IP rights on innovation.

Four theoretical [limit] situations are considered, each described by specific levels of inter and intra spillovers:

- First situation: perfect spillovers $(\delta, \beta)=(1,1)$, it is the case when IP rights are not protected. This models the situation in many LDCs preceding the adoption of IP agreements.

- Second situation: perfect inter spillovers and no intra spillovers, $(\delta, \beta)=(1,0)$, it is the case when LDC protects IP rights only for local firms. This is for example often the case in the artistic and cultural sectors where local innovators are more efficiently protected.

- Third situation: perfect intra spillovers and no inter spillovers $(\delta, \beta)=(0,1)$, it is the case when LDCs enforces TRIPs for international exchanges but not for local illegal knowledge transfer.

- Fourth situation: no spillovers, a complete control of spillovers $(\delta, \beta)=(0,0)$, this describes the idealistic situation when LDC enforces rigorously IP agreements for both local and international firms.

\section{Profits and R\&D Expenditures Without IP Protection}

Profits and R\&D expenditures of LDC and DC firms are compared in the case of $(\delta, \beta)=(1,1)$. This case models the situation prevailing in most developing countries before the adoption of TRIPs: both local and international illegal technology transfers are possible with no stringent sanctions. 
The discussions presented here and in the following subsections are based on the per-unit marginal costs of $\mathrm{R} \& \mathrm{D} \gamma_{D C}$ and $\gamma_{L D C}$ which model respectively the innovative abilities of the DC and the two LDC firms.

The following conditions [see inequalities (13)] are required to insure the uniqueness of Cournot-Nash and Nash equilibrium solutions:

$$
\gamma_{D C}>1 / 8 \text { and } \gamma_{L D C}>1 / 2
$$

Under the previous conditions, the non-negativity of cost reductions $\hat{x}_{1}=\hat{x}_{2}$ (denoted hereafter $\hat{x}$ ) and $\hat{y}$ [given by Eqs. (11) and (12)] requires the following condition

$$
\gamma_{L D C} \geq 2
$$

If such conditions hold, the difference between profits of each LDC firm and the DC firm writes:

$$
\pi_{L D C}-\pi_{D C}=\frac{1}{2}(a-c)^{2} \frac{\gamma_{D C}\left(28 \gamma_{D C} \gamma_{L D C}-32 \gamma_{D C}+4-4 \gamma_{L D C}+\gamma_{L D C}^{2}\right)}{\left(2-8 \gamma_{D C}-\gamma_{L D C}+8 \gamma_{D C} \gamma_{L D C}\right)^{2}} .
$$

Studying the sign of the previous expression shows that $\pi_{L D C} \geq \pi_{D C}$ for all $\gamma_{D C}>1 / 8$ and $\gamma_{L D C} \geq 2$. Consequently, without international IP agreements LDC firms will always have, according to this model, the highest profits.

The previous findings are summarised in Fig. 1. Figure 2 compares R\&D expenditures between each one of the LDC firms and the DC firm. The sign + means that each LDC firm will have higher R\&D invest than its DC rival.

As shown in Figs. 1 and 2, LDC firms will generally have more profits and more R\&D invests than the DC firm. The spillovers are too penalizing for the DC firm which is discouraged from investing a lot in such markets. A particular case occurs when the technological gap between DC and LDC firms is huge (see top left of Fig. 2), in such a case the advance of the DC firm is so important that it could have more R\&D expenses than LDC firms even in presence of high spillovers.

The previous results show that with lax enforcement of IP agreements and laws LDC firms would generally have more profits and more R\&D expenditures. The fact that imitation and counterfeiting are still permitted will maintain a dynamic local innovative network but will clearly restrain foreign innovative firms from investing heavily in high IP LDC markets.

\section{The Case of Local IP Protection}

The case of $(\delta, \beta)=(1,0)$ describes the situation where LDC deciders protect IP rights only for local innovators. The following conditions are required for uniqueness of the equilibrium solutions:

$$
\gamma_{D C}>1 / 8 \text { and } \gamma_{L D C}>9 / 8
$$

Under the previous conditions, the non-negativity of cost reductions $\hat{x}$ and $\hat{y}$ requires the following condition: $\gamma_{L D C} \geq 3 / 2$. 
Sign of PI_LDC - PI_DC (Case: delta=1,beta=1)

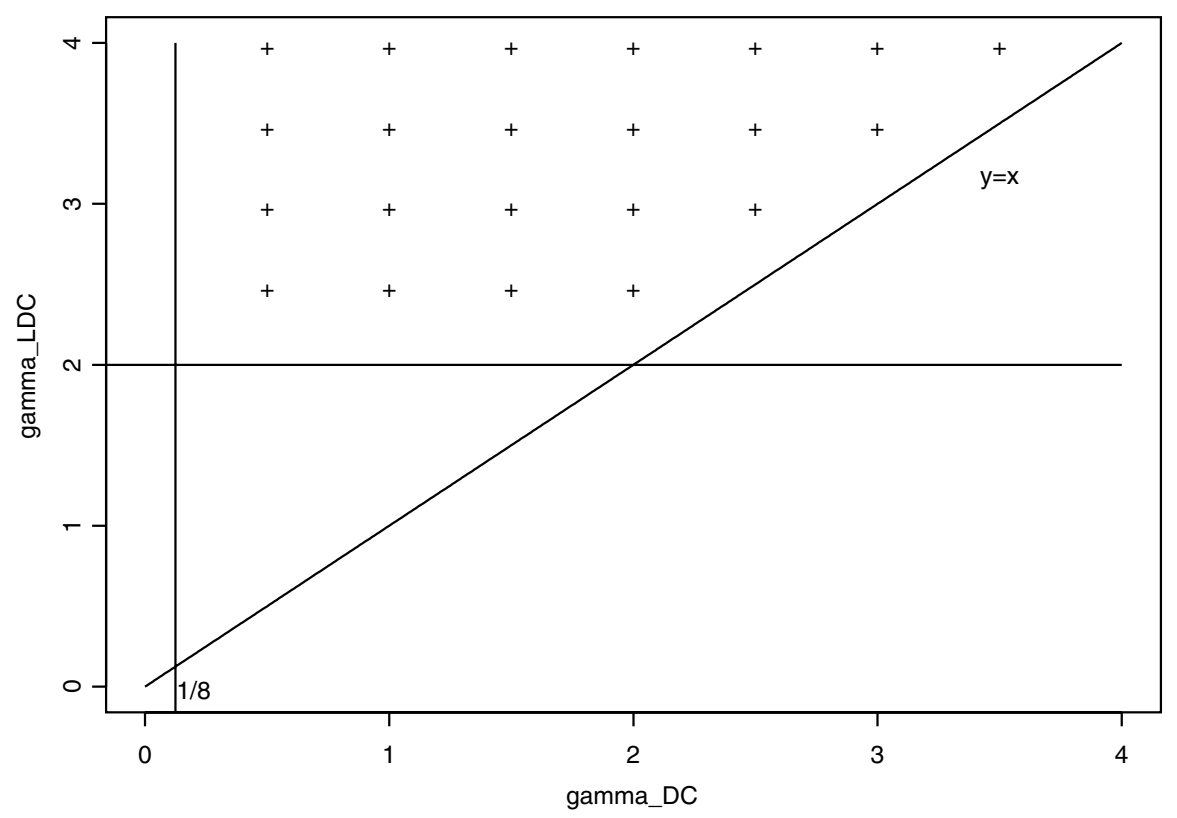

Fig. 1 Comparison of profits of LDC and DC firms in the case of complete spillovers: $(\delta, \beta)=(1,1)$

If the previous conditions hold, the difference between profits of one of the LDC firms and the DC firm writes:

$$
\pi_{L D C}-\pi_{D C}=\frac{1}{2} \frac{(a-c)^{2} \gamma_{D C}\left(60 \gamma_{D C} \gamma_{L D C}-72 \gamma_{D C}+9-12 \gamma_{L D C}+4 \gamma_{L D C}^{2}\right)}{\left(3-2 \gamma_{L D C}+16 \gamma_{D C} \gamma_{L D C}-12 \gamma_{D C}\right)^{2}} .
$$

The sign of the previous difference depends on the sign of:

$$
60 \gamma_{D C} \gamma_{L D C}-72 \gamma_{D C}+9-12 \gamma_{L D C}+4 \gamma_{L D C}^{2}
$$

which double root is: $\gamma_{L D C}^{\prime}=-\frac{15}{2} \gamma_{D C}+\frac{3}{2}+\frac{3}{2} \sqrt{25 \gamma_{D C}^{2}-2 \gamma_{D C}}$.

As $\gamma_{L D C}^{\prime}<3 / 2$ for all $\gamma_{D C}>1 / 8$, we have the following results:

- LDC firms have higher profits $\left(\pi_{L D C}>\pi_{D C}\right)$ for all $\gamma_{L D C} \geq 3 / 2$ and $\gamma_{D C}>1 / 8$.

Figs. 3 and 4 give respectively the comparison of profits and R\&D expenditures between one of the LDC firms and the DC firm.

Figures 3 and 4 are respectively very close to Figs. 1 and 2, so in presence of inter spillovers, it does not matter whether intra spillovers are allowed or not since in both cases LDC firms will have generally the greatest profits and R\&D 
Sign of RD Exp_LDC - RD Exp_DC (Case: delta=1,beta=1)

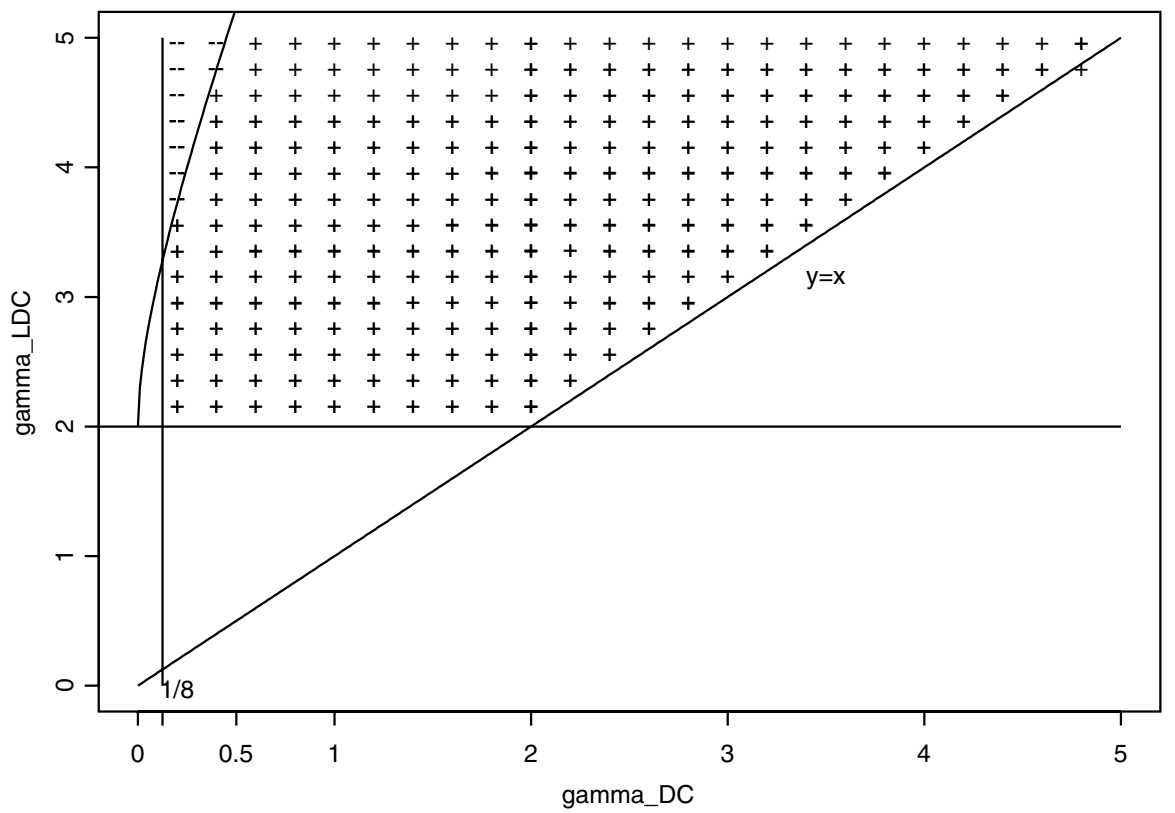

Fig. 2 Comparison of R\&D expenses of LDC and DC firms in the case of complete spillovers: $(\delta, \beta)=$ $(1,1)$

expenditures. The foreign firm, with its high innovative ability, will still be discouraged from investing in LDC-oriented R\&D.

\section{The Case of International IP Protection with Local Laxity}

The case of $(\delta, \beta)=(0,1)$ describes a transitory situation in LDCs where IP rights are supposed to be rigorously enforced only for international partners.

The uniqueness of Nash equilibrium solutions requires

$$
\gamma_{D C}>9 / 8 \text { and } \gamma_{L D C}>1 / 2 \text {. }
$$

Under the previous conditions, the non-negativity of cost reductions $\hat{x}$ and $\hat{y}$ requires:

$$
\gamma_{D C} \leq 3 / 2 \text { and } \gamma_{L D C} \leq 2 \text { or } \gamma_{D C} \geq 3 / 2 \text { and } \gamma_{L D C} \geq 2 .
$$

If the previous conditions hold, the difference between profits of one of the LDC firms and the DC firm writes:

$$
\pi_{L D C}-\pi_{D C}=-\frac{1}{2}(a-c)^{2} \frac{S\left(\gamma_{D C}, \gamma_{L D C}\right)}{\left(6-8 \gamma_{D C}-9 \gamma_{L D C}+8 \gamma_{D C} \gamma_{L D C}\right)^{2}}
$$


Sign of PI_LDC - PI_DC (Case: delta=1, beta=0)

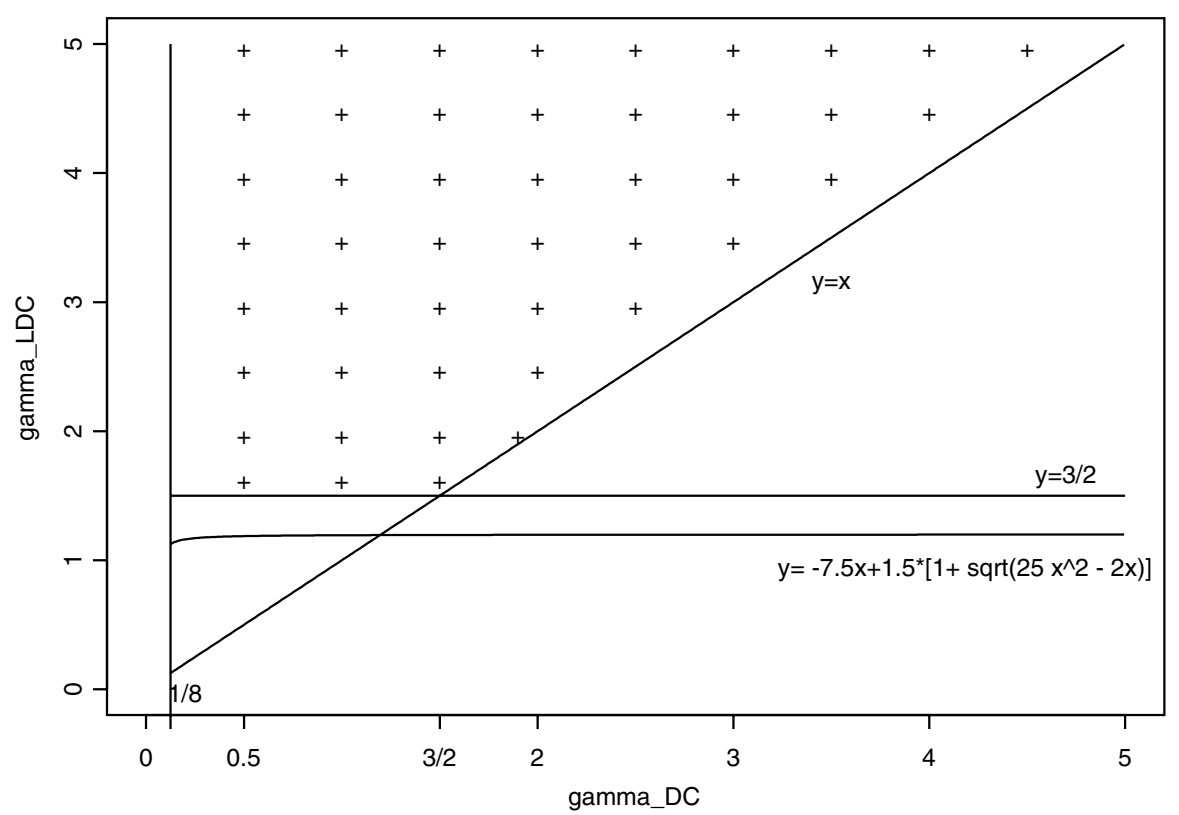

Fig. 3 Comparison of profits of LDC and DC firms in the case of no intra spillovers: $(\delta, \beta)=(1,0)$

where

$$
\begin{gathered}
S\left(\gamma_{D C}, \gamma_{L D C}\right)=-18 \gamma_{L D C}^{2}+15 \gamma_{L D C}^{2} \gamma_{D C}+9 \gamma_{L D C}+24 \gamma_{D C} \gamma_{L D C} \\
-28 \gamma_{L D C} \gamma_{D C}^{2}+32 \gamma_{D C}^{2}-36 \gamma_{D C}
\end{gathered}
$$

the sign of the difference $\pi_{L D C}-\pi_{D C}$ is the opposite of the sign of $S\left(\gamma_{D C}, \gamma_{L D C}\right)$ which may be seen as a second order equation with the unknown $\gamma_{L D C}$ and the discriminant

$$
\Delta\left(\gamma_{D C}\right)=784 \gamma_{D C}^{4}-3264 \gamma_{D C}^{3}+4536 \gamma_{D C}^{2}-2160 \gamma_{D C}+81
$$

It is easy to prove that the uniqueness condition $\gamma_{D C}>9 / 8$ implies that $\Delta\left(\gamma_{D C}\right)>0$ for all $\left.\gamma_{D C} \in\right] 9 / 8,+\infty[/\{3 / 2\}$ and $\Delta(3 / 2)=0$.

Consequently, the sign of $\pi_{L D C}-\pi_{D C}$ depends on the two roots of the expression (17) given hereafter:

$$
\gamma_{L D C}^{\prime}=\frac{28 \gamma_{D C}^{2}-24 \gamma_{D C}-9+\sqrt{784 \gamma_{D C}^{4}-3264 \gamma_{D C}^{3}+4536 \gamma_{D C}^{2}-2160 \gamma_{D C}+81}}{2\left(-18+15 \gamma_{D C}\right)}
$$


Sign of RD Exp_LDC - RD Exp_DC (Case: delta=1,beta=0)

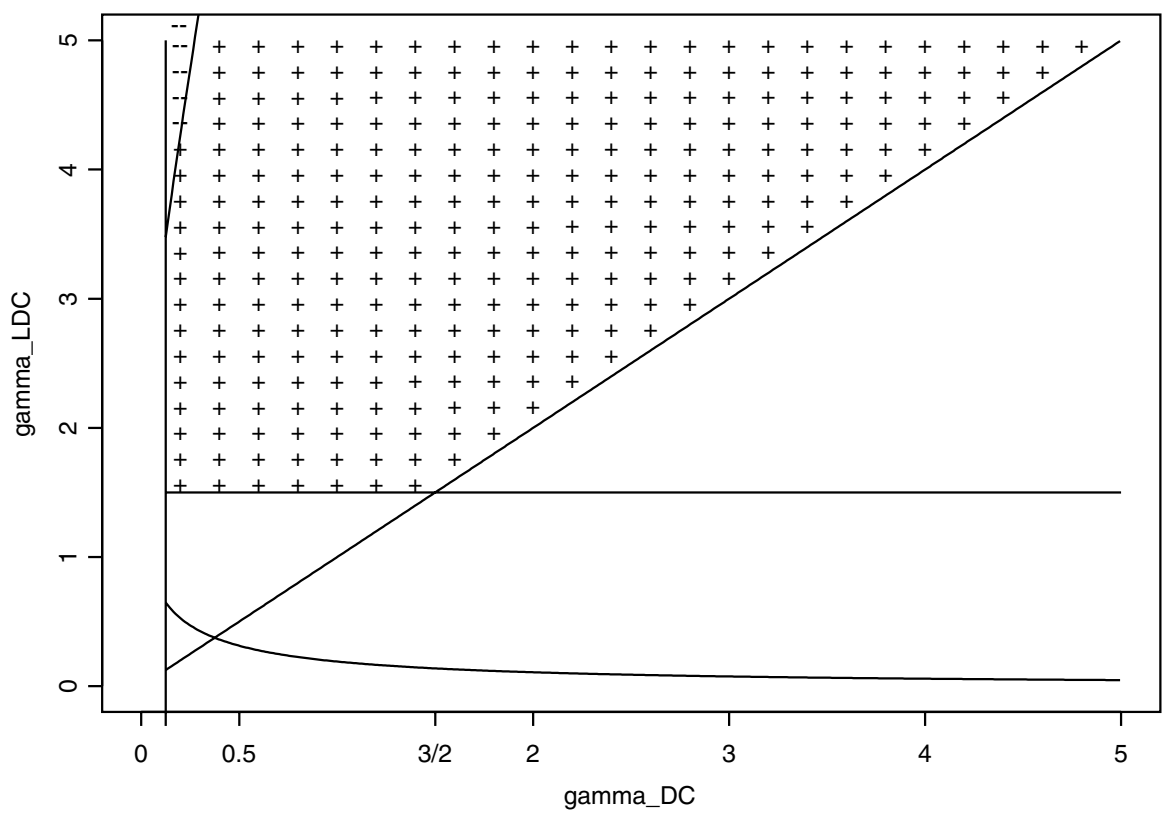

Fig. 4 Comparison of R\&D expenses of LDC and DC firms in the case of no intra spillovers: $(\delta, \beta)=$ $(1,0)$

$$
\gamma_{L D C}^{\prime \prime}=\frac{28 \gamma_{D C}^{2}-24 \gamma_{D C}-9-\sqrt{784 \gamma_{D C}^{4}-3264 \gamma_{D C}^{3}+4536 \gamma_{D C}^{2}-2160 \gamma_{D C}+81}}{2\left(-18+15 \gamma_{D C}\right)}
$$

Studying the different cases, we have the following results depending on the value of $\gamma_{D C}$ :

- for $\left.\gamma_{D C} \in\right] 9 / 8, r 2[$ where $r 2=1.218$ is the smallest root of the equation $\gamma_{L D C}^{\prime \prime}=\gamma_{D C}$ :

$$
\pi_{L D C} \geq \pi_{D C} \quad \forall \gamma_{L D C} \in\left[\gamma_{D C}, 2\right]
$$

- for $\left.\gamma_{D C} \in\right] r 1,3 / 2[/\{6 / 5\}$

$$
\begin{array}{ll}
\pi_{L D C}>\pi_{D C} & \forall \gamma_{L D C} \in\left[\gamma_{L D C}^{\prime \prime}, 2\right] \\
\pi_{L D C}<\pi_{D C} & \forall \gamma_{L D C} \in\left[\gamma_{D C}, \gamma_{D C}^{\prime \prime}[\right.
\end{array}
$$

- for $\left.\gamma_{D C} \in\right] 3 / 2,+\infty[$ 


$$
\begin{array}{ll}
\pi_{L D C}>\pi_{D C} & \forall \gamma_{L D C} \in\left[\max \left(2, \gamma_{D C}\right), \gamma_{L D C}^{\prime}\right] \\
\pi_{L D C}<\pi_{D C} & \forall \gamma_{L D C}>\gamma_{L D C}^{\prime} .
\end{array}
$$

The previous results are summarised in Fig. 5 and commented hereafter.

Results in Fig. 5 are commented using three regions:

- The first region is at the right side of Fig. 5, it is defined by $\gamma_{D C}>3 / 2$. This models high technological valued sectors (like Information and Communication technologies, Biotechnology, Nanotechnology and Aeronautics) for which DC firm will have more profits (Fig. 5) and more R\&D expenditures (Fig. 6) provided that its technological gap with LDC firms is important $\left(\gamma_{L D C}>\gamma_{L D C}^{\prime}\right)$. If this technological gap is small $\left(\gamma_{L D C}<\gamma_{L D C}^{\prime}\right)$, LDC firms will have more profits even if (see Fig. 6) it will not have necessarily the highest $R \& D$ expenditures. This could be explained by the fact that the assumption of perfect intra spillover $(\beta=1)$ and symmetric R\&D expenditures in LDC $\left(x_{1}=x_{2}\right)$ yields a tacit cooperation between LDC firms. Consequently, when TRIPs are rigorously enforced for inter spillovers, LDC firms could have more profits than the DC firm when intra spillovers are allowed and when the technological gap is not important.

- The second region (middle of Fig. 5) is defined by $\left.\left.\gamma_{D C} \in\right] r 2,3 / 2\right]$. This region corresponds to medium technological valued sectors. For such sectors, Fig. 5 shows

Sign of PI_LDC - PI_DC (Case: delta $=0$ and beta=1)

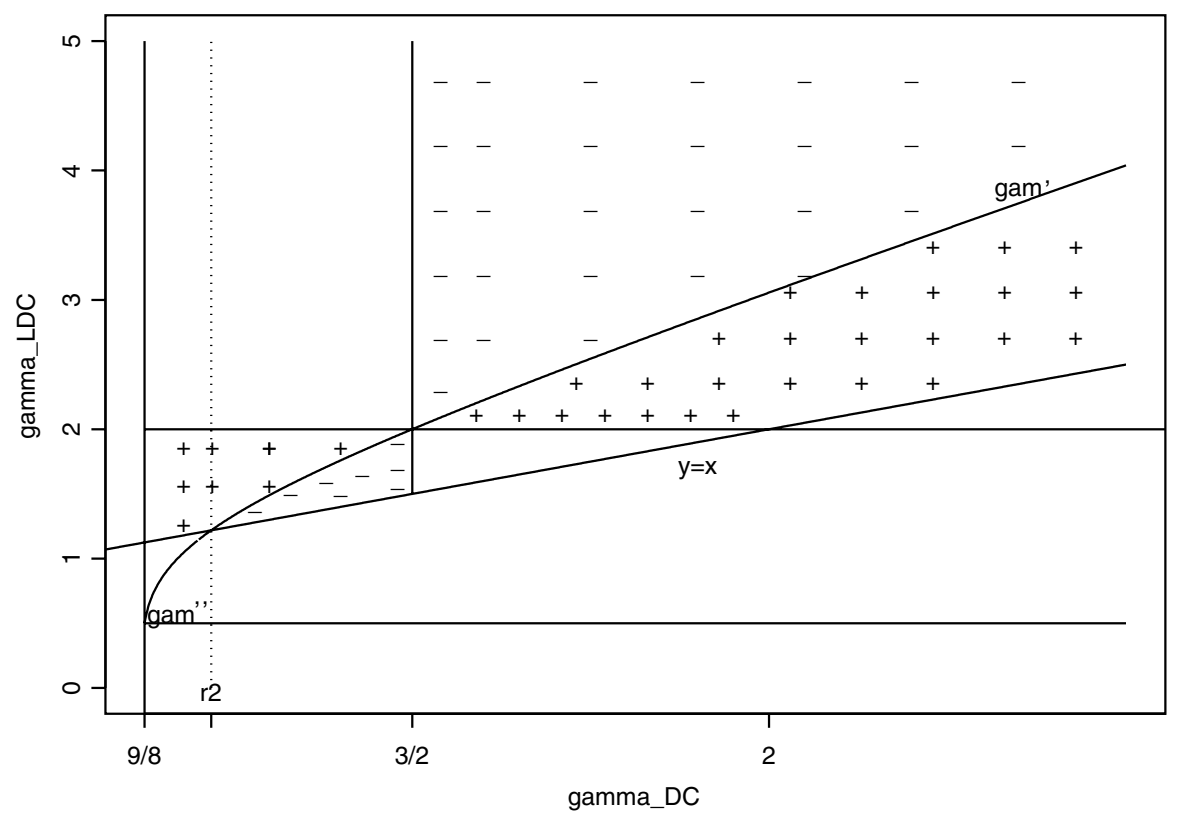

Fig. 5 Comparison of profits of LDC and DC firms in the case of complete intra spillovers: $(\delta, \beta)=(0,1)$ 
Sign of RD Exp_LDC - RD Exp_DC (Case: delta=0 and beta=1)

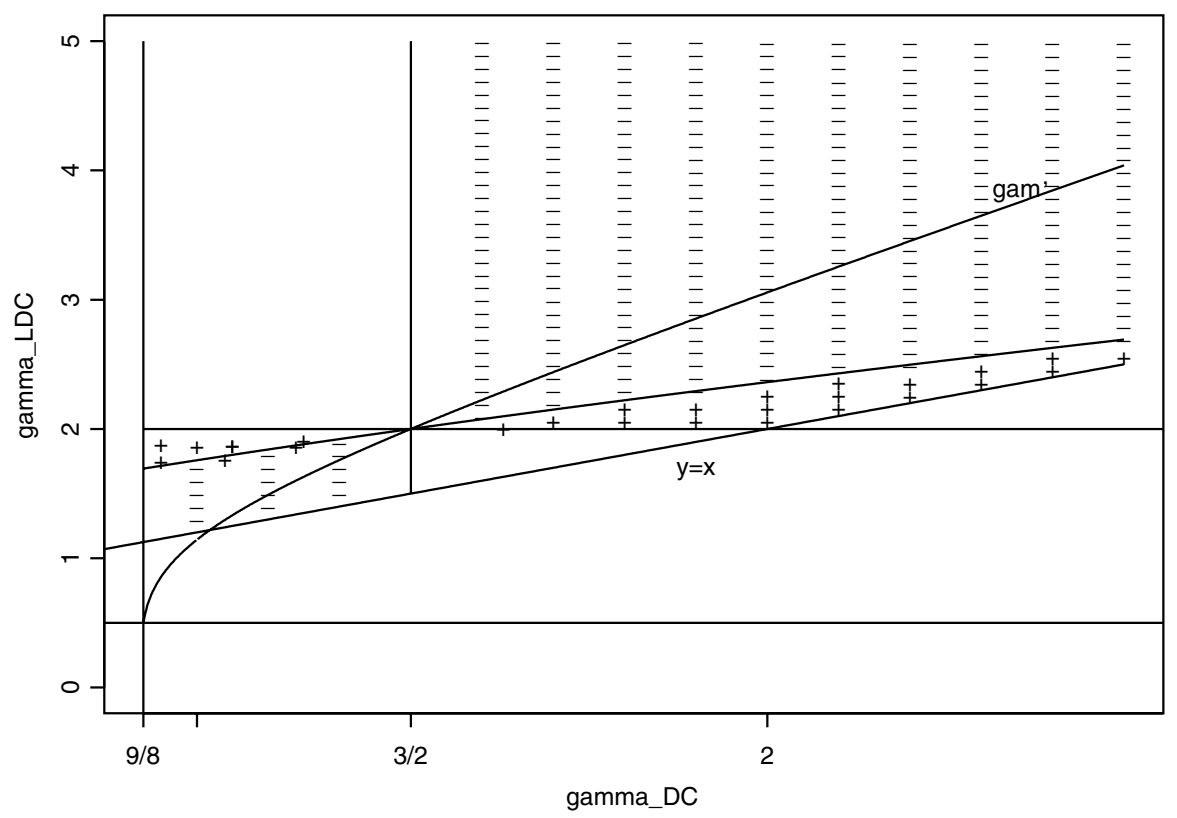

Fig. 6 Comparison of R\&D expenses of LDC and DC firms in the case of no inter spillovers: $(\delta, \beta)=$ $(0,1)$

that financial results of LDC and DC firms depend on the technological difference between LDC and DC (measured by $\gamma_{L D C}-\gamma_{D C}$ ). When the technological gap is small, the equilibrium solution yields the DC firm to have more profits (Fig. 5) and more R\&D invests (Fig. 6). But when the technological gap is more important it seems that the optimal strategic choice for the two (illegally associated) LDC firms is to invest more than the DC firm. Their cumulate R\&D efforts (possible due to lax local enforcements of IP agreements) will give each LDC firm more profits than its foreign rival.

- The last region is at the left of Fig. 5 is defined by $\left.\left.\gamma_{D C} \in\right] 9 / 8, r 2\right]$. This region could be related to low technological valued sectors (like agriculture and textile). LDC firms will always have more profits than DC firms despite the absence of inter spillovers. This could be explained by a weak profitability of R\&D investment. LDC firms in low technological valued sectors are competitive even if their R\&D costs are high. In this kind of sectors (see left side of Fig. 6) LDC firms will not be encouraged to work on R\&D activities unless their technological gap is important.

\section{R\&D Expenditures and Profits After Stringent Protection of IP Rights}

Profits and R\&D expenditures of LDC and DC firms are compared in the case where $(\delta, \beta)=(0,0)$. IP rights are rigorously protected in LDC for both local and 
foreign firms. It is assumed here that IP protection could provide firms a complete control of their spillovers.

In this case the following inequalities are needed for the uniqueness of the solutions:

$$
\gamma_{D C}>9 / 8 \text { and } \gamma_{L D C}>9 / 8
$$

The following conditions insure that the R\&D optimal efforts $x_{1}=x_{2}=\hat{x}$ and $\hat{y}$ (given by Eqs. (11) and (12)) are non-negative:

$$
\gamma_{D C} \leq 3 / 2 \text { and } \gamma_{L D C} \leq 3 / 2 \text { or } \gamma_{D C} \geq 3 / 2 \text { and } \gamma_{L D C} \geq 3 / 2
$$

Then, the profits difference is given by:

$$
\pi_{L D C}-\pi_{D C}=-\frac{3}{2} \frac{(a-c)^{2}\left(20 \gamma_{D C} \gamma_{L D C}-24 \gamma_{D C}+27-24 \gamma_{L D C}\right)\left(-\gamma_{D C}+\gamma_{L D C}\right)}{\left(9+16 \gamma_{D C} \gamma_{L D C}-12 \gamma_{D C}-18 \gamma_{L D C}\right)^{2}} .
$$

Studying the sign of the previous expression shows that

- LDC firms have higher profits $\left(\pi_{L D C}>\pi_{D C}\right)$ for $\gamma_{L D C}<3 / 2$ and $\gamma_{D C}<3 / 2$

- LDC firms have lower profits $\left(\pi_{L D C}<\pi_{D C}\right)$ for $\gamma_{L D C}>3 / 2$ and $\gamma_{D C}>3 / 2$

The previous findings are summarised in Fig. 7. The comparison of R\&D expenditures between the DC firm and each LDC firm shows that the firm with the highest profits will have the lowest R\&D expenditures. More precisely, the DC firm will have more profits with less R\&D expenditures in high technological sectors. The LDC firms inversely will have more profits and less R\&D efforts in low technological sectors. Moreover, the analysis of the equilibrium produced quantities shows that, for the realistic case where $\gamma_{L D C} \geq \gamma_{D C}$, the sign of $\pi_{L D C}-\pi_{D C}$ is the same that the sign of $q_{1}-q_{3}$. So generally firms make more profits when they produce more than their competitors.

Results of Fig. 7 are analysed according to two regions:

- The first region is at the left of Fig. 7 is defined by $\left.\gamma_{D C} \in\right] 9 / 8,3 / 2$ [, so it models low technological sectors. In this region $\pi_{L D C}-\pi_{D C}$ is always non-negative. Therefore, in low technological sectors, LDC firms would have greater profits with less R\&D expenditures. This could be explained by a week profitability of R\&D investment. LDC firms in low technological valued sectors will remain competitive even after more stringent IP protection.

- The second region is in the right side of Fig. 7, it is defined by $\gamma_{D C}>3 / 2$. This models high technological valued sectors for which the DC firm will systematically have more profits and less $R \& D$ costs. So after a future stringent enforcement of IP laws, DC firms will generally have the highest market shares in high technological sectors. This will incite highly innovative DC firms to work on specific needs of LDCs. On the other side LDC firms will have less profits, less market shares and much more R\&D efforts. To survive 


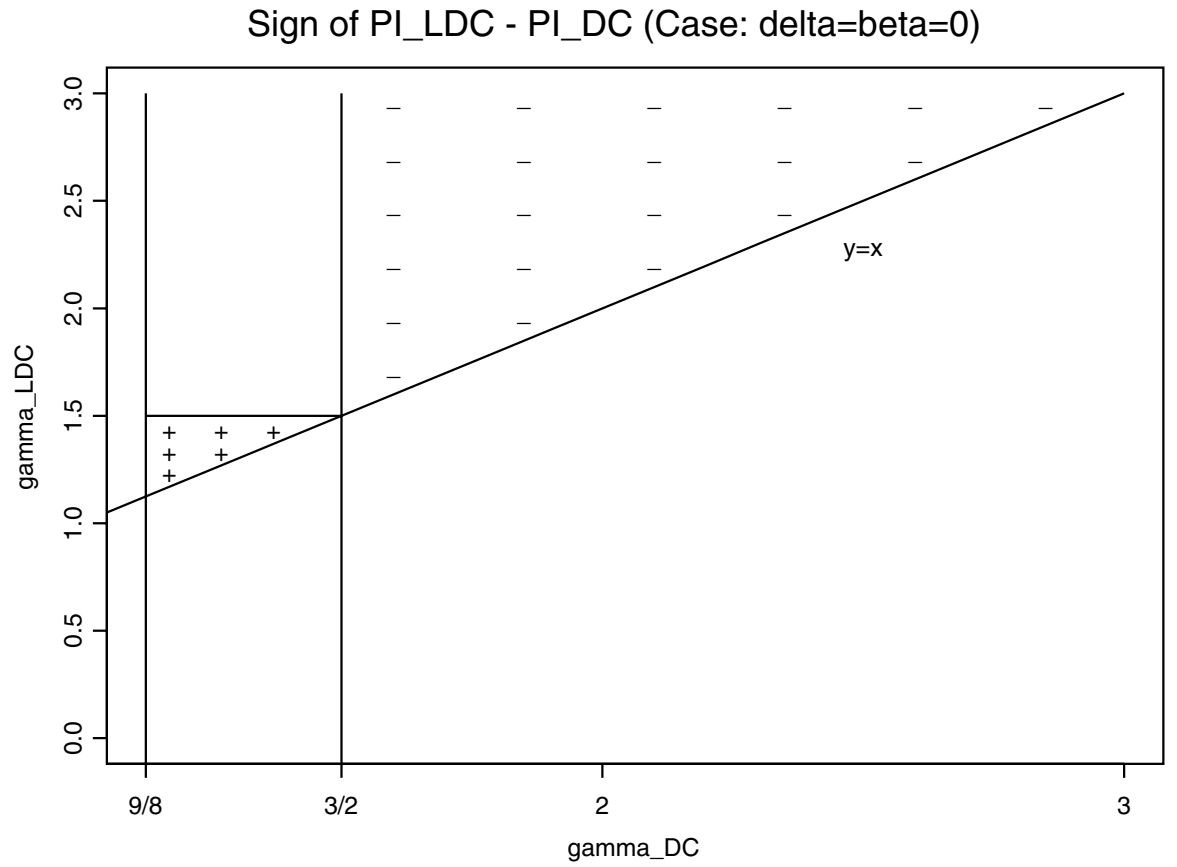

Fig. 7 Comparison of profits of LDC and DC firms in the case of no spillovers: $(\delta, \beta)=(0,0)$

in this new environment, local firms should increase their R\&D skills and reduce their technological gap otherwise they will disappear from their own high-tech markets. IP agreements could fulfil their objectives for such markets only if provisions concerning technology transfer to LDCs will be seriously implemented.

Remark In this case of stringent IP protection, LDC policy makers may encourage local firms to cooperate at least in the R\&D step. In this case a local R\&D partnership is organised and the two first equations in (10) are replaced by the following equation modelling a local $R \& D$ cooperation:

$$
\frac{\partial\left(\pi_{1}+\pi_{2}\right)}{\partial x}=\frac{1}{2}(a-c+2(1+\beta) x+(2 \delta-1) y)(1+\beta)-2 \gamma_{L D C} x=0
$$

giving with $(\delta, \beta)=(0,0): \frac{\partial\left(\pi_{1}+\pi_{2}\right)}{\partial x}=\frac{1}{2}(a-c+2 x-y)-2 \gamma_{L D C} x=0$.

The new equilibrium R\&D levels are given by the following equations (replacing respectively Eqs. (11) and (12): 


$$
\begin{aligned}
\hat{x}_{1}=\hat{x}_{2} & =\frac{3\left(2 \gamma_{D C}-3\right)(a-c)}{9-12 \gamma_{D C}-13.5 \gamma_{L D C}+12 \gamma_{D C} \gamma_{L D C}} \text { and } \\
\hat{y} & =\frac{3\left(1.5 \gamma_{L D C}-3\right)(a-c)}{9-12 \gamma_{D C}-13.5 \gamma_{L D C}+12 \gamma_{D C} \gamma_{L D C}}
\end{aligned}
$$

Figure 8 compares equilibrium R\&D invests with and without local R\&D cooperation. It appears clearly that local R\&D cooperation yields generally an increase in the R\&D invests of local firms (left side of Fig. 8) while generally (except for very low technological sectors) it yields the foreign firm to decrease its R\&D invest.

Figure 9 compares profits of local and foreign firms when IP are protected and local firms cooperate at the R\&D stage. It appears clearly that local LDC firms are now able to make more profits than their foreign competitor even for high technological sectors provided that their technological gap is not insuperable. This was impossible without local R\&D cooperation (see Fig. 7).

The comparison of Figs. 5 and 9 shows many similarities in the case of irregular (figure 5) and regular (Fig. 9) knowledge transfer between LDC firms.

\section{Discussion and Conclusion}

The model presented in this work is a first attempt to model and analyse future effects of international IP agreements on R\&D strategies in developing economies. A technological valued market in a developing economy was considered. Three firms compete in this market: two local firms with comparable innovative levels and a foreign firm with higher R\&D skills. The main results are summarised in Tables 1 and 2 for respectively high and low technological valued markets.

\section{Sign of $x_{-}$coop-x_nocoop}

\section{Sign of y_coop-y_nocoop}
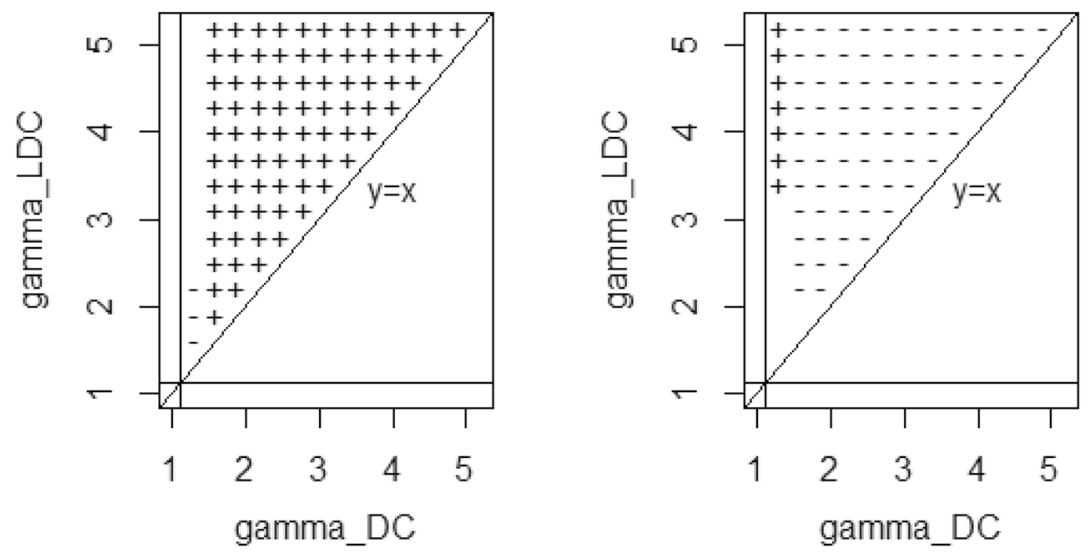

Fig. 8 Comparison of R\&D expenses with and without local R\&D cooperation after TRIPs adoption (left: LDC firms, right: DC firm) 


\section{Sign of PI_LDC-PI_DC \\ (Case: delta=beta $=0$ and local RD coop.)}

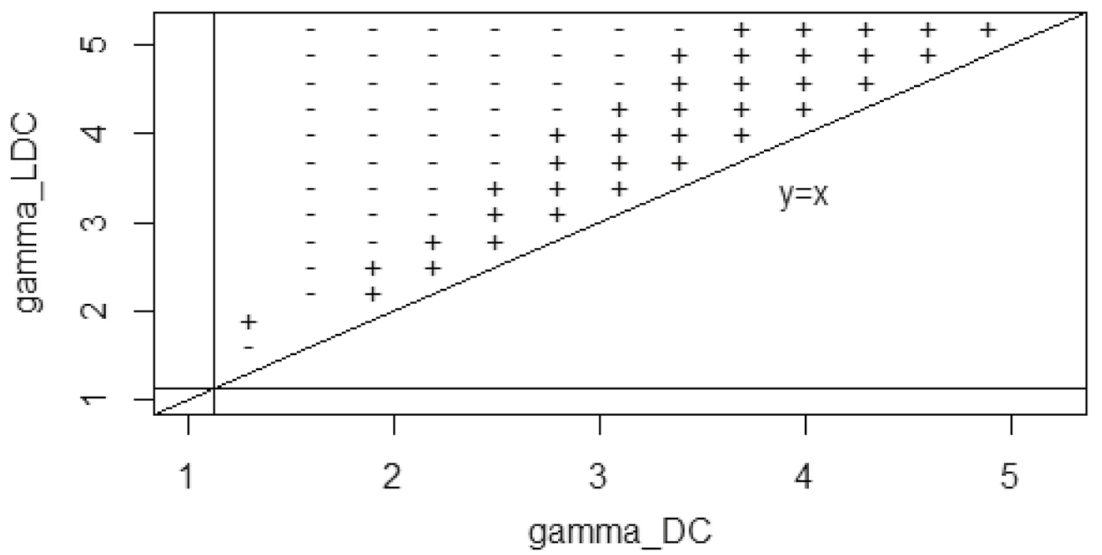

Fig. 9 Comparison of profits of LDC and DC firms in the case of TRIPs adoption and local R\&D cooperation

Table 1 Summary of the main results for High Technological valued sectors

\begin{tabular}{|c|c|c|}
\hline Type of IPR protection & Firm with higher profits & Firm with higher R\&D expen \\
\hline No protection $(\delta, \beta)=(1,1)$ & LDC & LDC except when techn. gap is huge \\
\hline $\begin{array}{l}\text { International protection but no local } \\
\text { protection in } \operatorname{LDC}(\delta, \beta)=(0,1)\end{array}$ & $\begin{array}{l}\text { LDC if low techn. gap; DC } \\
\text { if high techn. gap }\end{array}$ & $\begin{array}{l}\text { LDC if low techn. gap; DC if high } \\
\text { techn. gap }\end{array}$ \\
\hline Rigorous protection $(\delta, \beta)=(0,0)$ & $\mathrm{DC}$ & LDC \\
\hline $\begin{array}{l}\text { Rigorous protection with local R\&D } \\
\text { coop. }\end{array}$ & $\begin{array}{l}\text { LDC if low techn. gap; DC } \\
\text { if high techn. gap }\end{array}$ & $\begin{array}{l}\text { LDC if low techn. gap; DC if high } \\
\text { techn. gap }\end{array}$ \\
\hline
\end{tabular}

Table 2 Summary of the main results for Low Technological valued sectors

\begin{tabular}{|c|c|c|}
\hline Type of IPR protection & $\begin{array}{l}\text { Firm with } \\
\text { higher profits }\end{array}$ & Firm with higher R\&D expen \\
\hline No protection $(\delta, \beta)=(1,1)$ & LDC & LDC except when techn. gap is huge \\
\hline $\begin{array}{l}\text { International protection but no local protection } \\
\text { in } \operatorname{LDC}(\delta, \beta)=(0,1)\end{array}$ & LDC & $\begin{array}{l}\text { LDC if high techn. gap; DC if low } \\
\text { techn. gap }\end{array}$ \\
\hline Rigorous protection $(\delta, \beta)=(0,0)$ & LDC & $\mathrm{DC}$ \\
\hline
\end{tabular}

It was theoretically shown that when innovations of foreign firms are not protected, LDCs firms will have generally more profits and more R\&D expenditures regardless of the technological complexity of the studied market. 
When IP rights are stringently protected for both local and foreign firms, the latter will have more profits and less R\&D spending in high-tech sectors. Local firms will have much less market shares with much more R\&D expends.

On the other side, when IP rights are only protected for foreign firms (no inter spillovers) but illegal (or legal through R\&D partnership) knowledge exchanges are possible between local firms, our model suggests that, for high-tech markets, DC firms will have more profits and more R\&D expenditures only when the technological gap is important. The optimal strategy for LDC firms could be to have more R\&D expends with more profits, even in high-tech markets, when their innovation gap is not important and when intra spillovers (or tacit local cooperation) are still possible. Our model suggests that it would be more rationale for decision makers in LDCs to allow intra spillover (or initiate local R\&D cooperation) especially when the technological gap between the DC and LDC firms is not high. This joins the conclusions of Yang and Maskus (2009) about the fact that stronger IP protection will be beneficial only to LDCs with high absorptive capacity.

When TRIPs will be stringently enforced, intra and inter spillovers will be significantly decreased. In such cases the presented model gives economical equilibriums where :

- For high technological valued markets (Table 1), LDC firms will be forced to have more R\&D investments than their DC rival. But the latter will have more profits and more share markets since it has very high $R \& D$ investment returns.

- For low valued technological sectors (Table 2, LDC firms will generally have more profits and less R\&D investments. Local firms in low technological markets could continue making important profits even after more stringent IP protection.

It was also shown that a R\&D cooperation between LDC firms yields generally an increase of their optimal R\&D invests with possible leading position even in high technological markets provided that the technological gap with their foreign competitors is not high. Strengthening IP protection in LDCs should therefore be preceded by strong incentives for regulatory R\&D cooperation between local firms.

To discuss whether stronger IP protection will lead to higher local R\&D spending in LDCs, Fig. 10 compares R\&D efforts $\hat{x}$ of LDC firms before and after TRIPs adoption, the sign + means that LDC firms invest more in R\&D after TRIPs adoption. It is shown that for sectors with medium technological level, TRIPs will encourage LDC firms to invest more in R\&D. But for high-tech sectors, Fig. 10 shows that the enforcement of IP protection gives, for LDC firms, new Nash equilibrium with less $\mathrm{R} \& \mathrm{D}$ efforts.

The proposed model should help decision makers in LDCs to identify situations where it is profitable to enforce IP agreements and others where a tacit laxity could be provisionally essential for the survival of local innovative ecosystems.

The above analysis assumed that IP agreements will completely stop spillovers, this assumption is very restrictive since in real world, firms are not able to have a complete control of the flow of information resulting from their R\&D activities. As it was mentioned by Arrow (1962) several decades ago 'No amount of legal protection can make a thoroughly appropriable commodity of something so intangible as 
Sign of : RD Exp after TRIPs - RD Exp before TRIPs for LDC

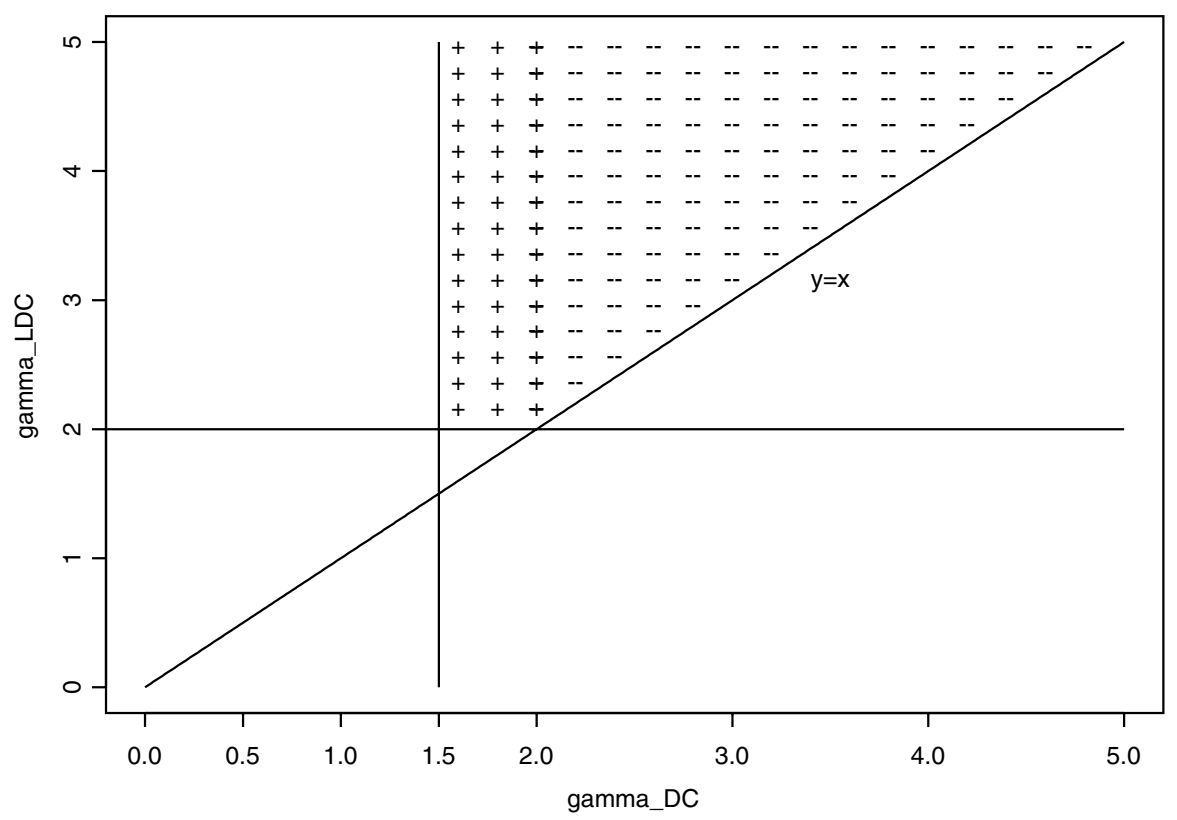

Fig. 10 Comparison of R\&D expenses of LDC firms before and after TRIPs adoption

information'. A more realistic model would consider that the rate of spillover will diminish (and not disappear) with IP agreements. Let us also note that our model does not capture an important property of R\&D processes: that of uncertainty. R\&D activities are risky, the present work could be extended by the introduction of uncertainty in the modelling of R\&D activities. The game used in this work is a one shot game, players took their decision taking in consideration the fact that they will not confront one another in future games. Future work should consider models with repeated games where R\&D strategies could change in time. This model considers a simultaneous game where players decide simultaneously and competitively on the quantity to produce after deciding their R\&D investments, this is why Nash-equilibrium solutions were used. A more realistic model will consider that the DC firm is the leader in the R\&D stage and the LDC firms are followers, thus a Stackelberg equilibrium should be used in the R\&D stage.

Future works will also develop optimal strategies of knowledge acquisition and R\&D in an increasing IP rights environment when:

- competing firms develop products distributed in both LDC and DC markets,

- different cooperative strategies are considered,

- both short-term and long-term macroeconomic IP agreements effects are modelled,

- social welfare implications of IP agreements are considered,

- ethical components are added to the utility functions of LDC firms, 
- incentives to DC firms for transferring technology to LDCs are modelled with different degrees of efficiency,

- firms from LDCs will have different R\&D strategies: some will invest to enhance their R\&D skills and others will continue imitation with the risk of having economic sanctions more or less likely depending on how IP agreements will be enforced.

\section{References}

Aldieri, L., V. Sena, and C. Vinci. 2018. Domestic r\&d spillovers and absorptive capacity: some evidence for US, Europe and Japan. International Journal of Production Economics 198: 38-49. https://doi. org/10.1016/j.ijpe.2018.01.015.

Amir, R. 2000. Modelling imperfectly appropriable R\&D via spillovers. International Journal of Industrial Organization 18: 1013-1032.

Arrow, K. 1962. The Rate and Direction of Innovative Activity, ed. Richard R. Nelson. Princeton University Press, chap Economic welfare and the allocation of resources for invention

Bouet, E. 2015. A study of intellectual property protection policies and innovation in the Indian pharmaceutical industry and beyond. Technovation 38: 31-41. https://doi.org/10.1016/j.technovation.2014. 10.007 .

Campi, M., and M. Dueñas. 2019. Intellectual property rights, trade agreements, and international trade. Research Policy 48 (3): 531-545. https://doi.org/10.1016/j.respol.2018.09.011.

Chen, Y., and T. Puttitanum. 2005. Intellectual property rights and innovation in developing countries. Journal of Development Economics 78: 474-493.

Cho, K., C. Kim, and S. Jhin. 2015. Differential effects of intellectual property rights on innovation and economic performance: a cross-industry investigation. Science and Public Policy. https://doi.org/10. 1093/scipol/scv009.

Cincera, M., Van Pottelsberghe, and B. de la Potterie. 2001. International R\&D spillovers: a survey. Cahiers Economiques de Bruxelles 169: 3-32.

Correa, C., and X. Seuba. 2019. Intellectual property and development: understanding the interfaces. Springer. https://doi.org/10.1007/978-981-13-2856-5

d'Aspremont, C., and A. Jacquemin. 1988. Cooperative and noncooperative R\&D in duopoly with spillovers. American Economic Review 78: 1133-1137.

Drahos, P. 2005. An alternative framework for the global regulation of intellectual property rights. Working paper, Centre for Governance of Knowledge and Development, The Australian National University, Australia

Drahos, P., and J. Braithwaite. 2002. Information feudalism: who owns the knowledge economy? London: Earthscan Publications Ltd.

Forero-Pineda, C. 2006. The impact of stronger intellectual property rights on science and technology in developing countries. Research Policy 35: 808-824.

Hudson, J., and A. Minea. 2013. Innovation, intellectual property rights, and economic development: a unified empirical investigation. World Development 46: 66-78. https://doi.org/10.1016/j.worlddev. 2013.01.023.

Kamien, M., E. Muller, and I. Zang. 1992. Research joint ventures and R\&D cartels. American Economic Review 82: 1293-1306.

Kim, Y., K. Lee, W. Park, and K. Choo. 2012. Appropriate intellectual property protection and economic growth in countries at different levels of development. Research Policy 41: 358-375. https://doi.org/ 10.1016/j.respol.2011.09.003.

Maskus, K., and D. Konan. 1994. Trade-related intellectual property rights: issues and exploratory results. Anal Negotiating Issues Global Trading Syst, pp 401-446, http://refhub.elsevier.com/ S0166-4972(14)00154-0/sbref28

Miyagiwa, K., and Y. Ohno. 2002. Uncertainty, spillovers and cooperative R\&D. International Journal of Industrial Organization 20: 855-876. 
Morin, J., and E. Gold. 2014. An integrated model of legal transplantation: the diffusion of intellectual property law in developing countries. International Studies Quarterly 58: 781-792.

Murray, F., and S. Stern. 2007. Do formal intellectual property rights hinder the free flow of scientific knowledge? An empirical test of the anti-commons hypothesis? Journal of Economic Behavior \& Organization 63: 648-687.

Papageorgiadis, N., and F. McDonald. 2019. Defining and measuring the institutional context of national intellectual property systems in a post-trips world. Journal of International Management 25 (1): 3-18. https://doi.org/10.1016/j.intman.2018.05.002.

Sampath, P. 2019. Intellectual property and development: understanding the interfaces, springer, chap intellectual property and technology transfer: why we need a new agenda. Springer. https://doi.org/ 10.1007/978-981-13-2856-5

Sweet, C., and D. Eterovic-Maggio. 2015. Do stronger intellectual property rights increase innovation? World Development 66: 665-677. https://doi.org/10.1016/j.worlddev.2014.08.025.

Sweet, C., and D. Eterovic. 2019. Do patent rights matter? 40 years of innovation, complexity and productivity. World Development 115: 78-93. https://doi.org/10.1016/j.worlddev.2018.10.009.

Tang, L., and P. Koveos. 2008. Embodied and disembodied R\&D spillovers to developed and developing countries. International Business Review 17: 546-558.

Yang, L., and K. Maskus. 2009. Intellectual property rights, technology transfer and exports in developing countries. Journal of Development Economics 90 (2): 231-236.

Publisher's Note Springer Nature remains neutral with regard to jurisdictional claims in published maps and institutional affiliations. 